\title{
Colonization Patterns of an mCherry-Tagged Pectobacterium carotovorum subsp. brasiliense Strain in Potato Plants
}

\author{
Gugulethu C. Kubheka, Teresa A. Coutinho, Ntsane Moleleki, and Lucy N. Moleleki
}

First, second, and fourth authors: Department of Microbiology and Plant Pathology, Forestry Agriculture and Biotechnology Institute (FABI), University of Pretoria, Lunnon Road, Pretoria, South Africa; and third author: National Advisory Council on Innovation, Private Bag, X894, Pretoria, South Africa.

Accepted for publication 29 May 2013.

\begin{abstract}
Kubheka, G. C., Coutinho, T. A., Moleleki, N., and Moleleki, L. N. 2013. Colonization patterns of an mCherry-tagged Pectobacterium carotovorum subsp. brasiliense strain in potato plants. Phytopathology 103:1268-1279.

Pectobacterium carotovorum subsp. brasiliense is a newly identified member of the potato soft rot enterobacteriaceae. The pathogenesis of this pathogen is still poorly understood. In this study, an mCherry-P. carotovorum subsp. brasiliense-tagged strain was generated to study $P$. carotovorum subsp. brasiliense-potato plant interactions. Prior to use, the tagged strain was evaluated for in vitro growth, plasmid stability, and virulence on potato tubers and shown to be similar to the wild type. Four potato cultivars were evaluated for stem-based resistance against $P$. carotovorum subsp. brasiliense. Confocal laser-scanning microscopy and in vitro viable cell counts showed that $P$. carotovorum subsp. brasiliense is
\end{abstract}

ABSTRACT

Members of the soft rot Enterobacteriaceae (SRE) occur in two main genera, Pectobacterium and Dickeya $(6,9)$. Collectively, they are responsible for the soft rot-blackleg/wilt disease complex in a large number of crop and ornamental plants. In the potato industry, the SRE cause major potato yield losses experienced both in the field and during storage. Four major Pectobacterium spp. are important in potato production globally: Pectobacterium carotovorum subsp. carotovorum, $P$. carotovorum subsp. brasiliense, $P$. atrosepticum, and $P$. wasabiae. In South Africa, two of these species, $P$. carotovorum subsp. brasiliense and $P$. wasabiae, have been identified as the main causal agents of soft rot and black leg diseases of potato $(30,39)$.

$P$. carotovorum subsp. brasiliense (formerly $P$. carotovorum brasiliensis) was first reported in Brazil in 2004 and has since been fully described $(18,31)$. Previous studies have shown $P$. carotovorum subsp. brasiliense strain 1692 (the strain for which a genome sequence is available) to be highly aggressive and more invasive compared with the well-studied $P$. atrosepticum $(29,30)$. Genome comparisons of $P$. carotovorum subsp. brasiliense, $P$. carotovorum subsp. carotovorum, and $P$. atrosepticum also indicated a subset of genes common between $P$. carotovorum subsp. brasiliense and $P$. carotovorum subsp. carotovorum that may likely account for the increased virulence observed in $P$. carotovorum subsp. brasiliense compared with P. atrosepticum (21). However, compared with $P$. atrosepticum and $P$. carotovorum

Corresponding author: L. N. Moleleki; E-mail address: lucy.moleleki@up.ac.za

*The $\boldsymbol{e}$-Xtra logo stands for "electronic extra" and indicates that Figures 1, 2, 4, 5, and 6 appear in color online.

http://dx.doi.org/10.1094/PHYTO-02-13-0049-R

(c) 2013 The American Phytopathological Society able to penetrate roots of a susceptible potato cultivar as early as $12 \mathrm{~h}$ postinoculation and migrate upward into aerial stem parts. Due to the phenotypic differences observed between tolerant and susceptible cultivars, a comparison of $P$. carotovorum subsp. brasiliense colonization patterns in these cultivars was undertaken. In the susceptible cultivar, $P$. carotovorum subsp. brasiliense cells colonized the xylem tissue, forming "biofilm-like" aggregates that led to occlusion of some of the vessels. In contrast, in the tolerant cultivar, $P$. carotovorum subsp. brasiliense appeared as free-swimming planktonic cells with no specific tissue localization. This suggests that there are resistance mechanisms in the tolerant cultivar that limit aggregation of $P$. carotovorum subsp. brasiliense in planta and, hence, the lack of symptom development in this cultivar.

Additional keyword: Dickeya.

subsp. carotovorum, the pathogenesis of $P$. carotovorum subsp. brasiliense is still poorly understood. Understanding the biology, ecology, and dissemination of Pectobacterium spp. from soil to roots or aerial parts of the plants, from seed to progeny tubers, as well as from infected to uninfected host plants is of significant importance (3).

Infected seed potato tubers and soil are important sources of inocula for the SRE (35). Of the different SRE, the newly established clade Dickeya biovar 3, also known as Dickeya solani, was shown to be capable of direct root penetration from soilborne inoculum (12). Furthermore, D. solani has been shown to be extremely aggressive and its ability to infect directly from the soil would seem to suggest that it is a better invader than other Pectobacterium spp. such as $P$. atrosepticum $(12,38)$. However, the ability or inability to infect roots from soil has not been demonstrated for most members of the SRE and certainly not for the newly identified $P$. carotovorum subsp. brasiliense.

Although it is generally accepted that contaminated seed tubers or soil are the main source of inoculum for tuber soft rot and blackleg diseases, there are other factors that warrant consideration. For example, aerial infection of potato plants via small airor waterborne (i.e., wind damage and irrigation water, respectively) SRE inoculum can also result in blackleg or aerial stem rots under wet conditions $(5,25,35)$. Alternatively, aerial infections can occur as a result of animal and human activities or the use of mechanically contaminated machinery. Furthermore, insects have been shown to be capable of serving as vectors in such cases and, thus, may present an alternative transmission pathway for bacterial pathogens $(3,22)$.

Therefore, the aim of this study was to determine the ability of $P$. carotovorum subsp. brasiliense to infect intact potato roots from available soil inoculum and to compare colonization patterns of $P$. carotovorum subsp. brasiliense strain in stems of potato 
cultivars with varying degrees of tolerance to $P$. carotovorum subsp. brasiliense infection. To study these different aspects of $P$. carotovorum subsp. brasiliense pathogenesis, the wild-type $P$. carotovorum subsp. brasiliense strain 1692 was transformed with a plasmid harboring the mCherry fluorescent protein and the mCherry-tagged $P$. carotovorum subsp. brasiliense strain was evaluated for virulence, growth rate, and plasmid stability prior to use.

\section{MATERIALS AND METHODS}

Bacterial strains and growth conditions. In all experiments an mCherry-tagged strain of Pectobacterium carotovorum subsp. brasiliense 1692 or wild-type $P$. carotovorum subsp. brasiliense 1692 (A. O. Charkowski, University of Winsconsin-Madison) were used. Strains were cultured at $28^{\circ} \mathrm{C}$ in Luria-Bertani (LB) broth for $16 \mathrm{~h}$ or on nutrient agar (NA) or crystal violet pectate (CVP) for 24 to $48 \mathrm{~h}$. For the mCherry-tagged strain, the medium was supplemented with tetracycline (Duchefa Biochemie, the Netherlands) to a final concentration of $16 \mu \mathrm{g} / \mathrm{ml}$. All reagents used were obtained from Merck (South Africa) unless otherwise stated. Prior to plant or tuber inoculations, overnight cultures of $P$. carotovorum subsp. brasiliense 1692 and $P$. carotovorum subsp. brasiliense mCherry strains were prepared in LB broth and grown to a cell density of an optical density at $600 \mathrm{~nm}\left(\mathrm{OD}_{600}\right)=$ $1\left(\approx 1 \times 10^{8} \mathrm{CFU} / \mathrm{ml}\right)$, washed, and resuspended in $10 \mathrm{mM}$ $\mathrm{MgSO}_{4}$.

Construction of mCherry-tagged $P$. carotovorum subsp. brasiliense strain. A plasmid (pMP7604) harboring mCherry (27) was used to generate an mCherry-tagged $P$. carotovorum subsp. brasiliense strain. The plasmid was introduced into bacterial cells by electroporation. Briefly, suspensions of $\approx 100 \mu \mathrm{l}$ of competent $P$. carotovorum subsp. brasiliense cells were mixed with $2 \mu \mathrm{l}$ of plasmid DNA and electro-shocked at $2.5 \mathrm{kV}$ for $\approx 5 \mathrm{mSec}$ (pulse controller resistance of $200 \Omega$ ) at $4^{\circ} \mathrm{C}$ using an Eppendorf Multiporator (Humburg, Germany). Cells were then resuscitated for $1 \mathrm{~h}$ in $1 \mathrm{ml}$ of $\mathrm{LB}$ broth at $28^{\circ} \mathrm{C}$ with shaking at $200 \mathrm{rpm}$. Transformed cells $(100 \mu \mathrm{l})$ were plated on NA plates supplemented with tetracycline and incubated for $48 \mathrm{~h}$ at $28^{\circ} \mathrm{C}$ for selection of positive transformants. The identity of transformants was confirmed with CVP plating and $P$. carotovorum subsp. brasiliense species-specific polymerase chain reaction (PCR), based on BR1f/L1r primers (5'-GCGTGCCGGGTTTATGACCT$\left.3^{\prime} / 5^{\prime}-\mathrm{CA}(\mathrm{A} / \mathrm{G}) \mathrm{GGCATCCACCGT}-3^{\prime}\right)$ as previously reported by Duarte et al. (18). The presence of pMP7604-mCherry in transformants was confirmed by fluorescence microscopy.

Maintenance of the pMP7604-mCherry plasmid in $P$. carotovorum subsp. brasiliense in vitro. Maintenance of the plasmid carrying the $m$ Cherry gene in $P$. carotovorum subsp. brasiliense cells was evaluated by measuring fluorescence of mCherry- $P$. carotovorum subsp. brasiliense maintained in LB broth supplemented with tetracycline (positive control) or without antibiotic for a period of 22 days. Overnight bacterial cultures at a density of $1 \times 10^{8} \mathrm{CFU} / \mathrm{ml}$ were freshly subcultured at a ratio of 1:100 daily into LB broth with or without antibiotic. On every third day before subculturing, samples were collected to measure fluorescence of the mCherry- $P$. carotovorum subsp. brasiliense strain harboring plasmid pMP7604 on a Fluoroskan Ascent FL as follows. Overnight bacterial cultures were washed and resuspended in $200 \mu \mathrm{l}$ of distilled water $\left(\mathrm{dH}_{2} \mathrm{O}\right)$. Subsequently, $100 \mu \mathrm{l}$ of each culture suspension was added into the wells of a black 96well flat-bottomed microtiter plate (Thermo Labsystems, Finland). Fluorescence was quantified using an excitation of $530 \mathrm{~nm}$ and emission at $630 \mathrm{~nm}$. The Fluoroskan data were supplemented with plate colony counts. CFU were determined every third day as follows: $1 \mathrm{ml}$ of the overnight bacterial cultures was washed in $\mathrm{dH}_{2} \mathrm{O}$ and serial dilutions were prepared and plated on NA plates with and without tetracycline. The resulting numbers of viable cells were compared. Each experiment was conducted in triplicate with three independent biological repeats.

Growth of the mCherry-tagged compared with wild-type strain. To assess bacterial growth of the mCherry-tagged $P$. carotovorum subsp. brasiliense compared with the wild-type strain, overnight bacterial culture, with a density of $10^{8} \mathrm{CFU} / \mathrm{ml}$ in LB broth, was diluted 50 times with LB broth. Bacteria were grown at $28^{\circ} \mathrm{C}$ with shaking at $200 \mathrm{rpm}$. Growth rate was determined by measuring the $\mathrm{OD}_{600}$ at regular intervals for a period of $21 \mathrm{~h}$ and the rates of the two strains were compared. This experiment was conducted in triplicate and two biological replicates.

Maceration ability of the mCherry-tagged strain compared with the wild type. The ability of mCherry-tagged $P$. carotovorum subsp. brasiliense to macerate tuber tissue was evaluated compared with the wild-type strain in a tuber soft rot virulence assay. Overnight bacterial culture in LB broth was washed and resuspended in $10 \mathrm{mM} \mathrm{MgSO}_{4}$ to a density of $10^{8} \mathrm{CFU} / \mathrm{ml}$ $\left(\mathrm{OD}_{600}=1\right)$. Commercial potato tubers were rinsed with running tap water, then soaked in 5\% commercial bleach (sodium hypochlorite) with a few drops of Tween 20 for $20 \mathrm{~min}$, and finally soaked in $\mathrm{dH}_{2} \mathrm{O}$ for $20 \mathrm{~min}$ before being air dried. Bacterial cultures $(10 \mu \mathrm{l})$ were stab inoculated with $100-\mu \mathrm{l}$ pipettes into $\approx 1$-cm-deep holes and sealed with Vaseline to prevent drying. Tubers were incubated in humid plastic containers at $28^{\circ} \mathrm{C}$ for 3 days. After incubation, the rotten tissue was scooped out and weighed to quantify maceration ability (32). The results were compared with those of the wild-type and $\mathrm{MgSO}_{4}$ (negative control)-inoculated potato tubers. The experiment consisted of six potato tubers and two biological replicates.

Potato cultivar susceptibility or resistance evaluation assays. Stem inoculation experiments were conducted to compare susceptibility and resistance levels of four potato cultivars (Solanum tuberosum 'Mondial', 'BP1', 'Buffelspoort', and 'Valor') to $P$. carotovorum subsp. brasiliense stem infection. Seed tubers of the cultivars were planted in 2-liter plastic pots in a greenhouse and grown for 4 to 5 weeks with a photoperiod of 16 and $8 \mathrm{~h}$ (day and night, respectively) at 22 to $26^{\circ} \mathrm{C}$ and $70 \%$ relative humidity. Plants were watered every second day but not on the day of inoculation. Prior to inoculation, variable phenotypic characteristics between the different potato cultivars were noted. Thereafter, three stems per plant (12 plants per cultivar) were inoculated with $10 \mu \mathrm{l}$ of the $1 \times 10^{8} \mathrm{CFU} / \mathrm{ml}$ overnight cultures of mCherrytagged $P$. carotovorum subsp. brasiliense suspended in $10 \mathrm{mM}$ $\mathrm{MgSO}_{4}$ or $10 \mathrm{mM} \mathrm{MgSO}_{4}$ (as negative controls) at $\approx 10 \mathrm{~cm}$ above the soil level at the lower junction of the stem and leaflet. This was done using a $200-\mu$ l pipette tip, which was stabbed halfway into the stem at an angle of $45^{\circ}$. The inoculated part of the stem was then sealed with parafilm to prevent desiccation and leakage of inoculum down the stem or into the soil (11). Following inoculation, plants were watered every second day from the bottom of the pots $(12,30)$. To determine the relative susceptibility or resistance level of each cultivar, inoculated plants were evaluated daily for development of blackleg symptoms for 21 days. Quantitative rating was achieved by enumerating the number of asymptomatic versus symptomatic stems, and the average mean size of blackleg lesions on stems was calculated. At least 12 potato plants per treatment for each cultivar were used and the experiment was repeated at least twice.

Inoculations with mCherry-tagged $P$. carotovorum subsp. brasiliense. Soil inoculations. The mCherry-tagged $P$. carotovorum subsp. brasiliense strain was used to evaluate $P$. carotovorum subsp. brasiliense potato plant root invasion and colonization from soil inoculum. For this experiment, a single cultivar evaluated as highly susceptible to $P$. carotovorum subsp. brasiliense was used. Seed tubers of the susceptible potato cultivar were planted as described for susceptibility or resistance evaluation assays. At 4 to 5 weeks, while avoiding disturbing the plants, the roots from half the total number of potato plants were wounded 
by cutting off $\approx 30 \%$ with a sterile pair of scissors. All plants with cut or uncut root systems were watered at least an hour before soil inoculation. Inoculation of soil was conducted according to Czajkowski et al. (12) with minor modifications. Briefly, the lower parts of the pots $(25 \%)$ were immersed overnight in $200 \mathrm{ml}$ of suspensions of mCherry- $P$. carotovorum subsp. brasiliense at $10^{8} \mathrm{CFU} / \mathrm{ml}$ or bacteria-free $10 \mathrm{mM} \mathrm{MgSO}_{4}$. After inoculation, plants were left unwatered for at least $24 \mathrm{~h}$. The experiment consisted of 12 plants and two independent biological replicates. Roots and stems of three randomly selected plants were harvested for a period of 21 days at four time points $(12 \mathrm{~h}$ postinoculation [hpi] and 7, 14, and 21 days postinoculation [dpi]). Representative, randomly selected root samples $(\approx 4 \mathrm{~g}$ each) from the three plants were used for subsequent evaluations. For stems, 2-cm-thick fragments from each of the three plants at $10 \mathrm{~cm}$ above soil surface were harvested.

Stem inoculations. Two potato cultivars (BP1 and Valor) with differing levels of resistance to $P$. carotovorum subsp. brasiliense were selected. Stems were inoculated with $10 \mu \mathrm{l}$ of mCherry- $P$. carotovorum subsp. brasiliense at $1 \times 10^{8} \mathrm{CFU} / \mathrm{ml}$ suspended in $10 \mathrm{mM} \mathrm{MgSO}_{4}$, as previously outlined. The experiment consisted of 21 plants and two independent replicates. Three asymptomatic stems of the resistant or susceptible cultivar were harvested at each time by cutting 2-cm-thick stem fragments $6 \mathrm{~cm}$ above and below the point of inoculation (POI). The following sampling intervals were undertaken: 3, 6, 9, 12, 17, and $21 \mathrm{dpi}$.

Evaluation of potato plant root and stem colonization by mCherry-tagged $\boldsymbol{P}$. carotovorum subsp. brasiliense. Root and stem colonization patterns of soil-inoculated mCherry-tagged $P$. carotovorum subsp. brasiliense were quantitatively and qualitatively evaluated. Prior to evaluation, harvested roots were thoroughly rinsed with water and all harvested plant material was surface sterilized, as described by Czajkowski et al. (12). Briefly, sampled plant material was washed in running tap water to remove soil particles, then surface sterilized with $70 \%$ ethanol for $1 \mathrm{~min}$, washed three times with $\mathrm{dH}_{2} \mathrm{O}$ for $1 \mathrm{~min}$, soaked in $1 \%$ commercial bleach (sodium hypochlorite) for $4 \mathrm{~min}$, and finally washed three times with $\mathrm{dH}_{2} \mathrm{O}$ for $4 \mathrm{~min}$. Subsequently, roots $(\approx 4$ g) were ground using pestle and mortar. Stem fragments $(2 \mathrm{~cm}$ thick) from the three plants were chopped into small pieces using a sterile scalpel and $\approx 0.5 \mathrm{~g}$ of material was sampled. Weighed root and stem plant material was added to 0.4 and $0.5 \mathrm{ml}$, respectively, of one-quarter Ringer's solution and incubated with shaking at $200 \mathrm{rpm}$ for $20 \mathrm{~min}$ at $28^{\circ} \mathrm{C}$. To determine viable bacteria counts, serial dilutions of suspended plant material were conducted and suspensions were plated in triplicates on LB agar plates supplemented with tetracycline. The identity of recovered viable mCherry-tagged $P$. carotovorum subsp. brasiliense cells was confirmed using CVP and fluorescence microscopy, as described below.

Microscopic observations. Fluorescence microscopy. A Zeiss Axiovert200 fluorescence microscope (München, Germany) was used to confirm the identity of recovered viable and tetracyclineresistant mCherry- $P$. carotovorum subsp. brasiliense colonies from inoculated roots and stems. Bacterial colonies on CVP were viewed under a $\times 10$ objective with the following filter sets: $510 / 20 \mathrm{~nm}$ excitation with 560/40 nm emission for mCherry.

Confocal laser-scanning microscopy. In order to visually evaluate the presence of the mCherry-tagged $P$. carotovorum subsp. brasiliense cells in the roots and stems of potato plants, randomly selected root fragments $(2 \mathrm{~cm})$ and thin cross-sections of the harvested 2-cm-thick stem fragments were mounted on microscope glass slides with double-sided carbon tape, then examined for tissue colonization. The mCherry fluorescence was visualized with a Zeiss 510 META CSLM (Jena, Germany) using a 560- to 615 -nm band pass filter under $\mathrm{a} \times 10$ and $\times 63$ oil objective.

Statistical analysis. All statistical analyses were conducted using JMP v.5 software (SAS Institute Inc., Cary, NC), in which an analysis of variance at a 95\% confidence level and a Student's $t$ test for mean comparisons were used. To achieve approximate normality, the data were log transformed after adding a value of one to avoid taking logs of zero.

\section{RESULTS}

Construction of mCherry-tagged $\boldsymbol{P}$. carotovorum subsp. brasiliense. Following transformation of wild-type $P$. carotovorum subsp. brasiliense strain 1692 with pMP7604, transformant colonies were selected based on their acquired tetracycline resistance. Formation of cavities on CVP and amplification of a 322-bp PCR product confirmed the identity of the transformants as $P$. carotovorum subsp. brasiliense. Expression of mCherry in the transformants was confirmed with confocal laser-scanning microscopy (CLSM), which demonstrated that the $P$. carotovorum subsp. brasiliense-mCherry constitutively and strongly expressed mCherry in P. carotovorum subsp. brasiliense. A highly fluorescent colony was then randomly selected for further assays.

Characterization of the mCherry-P. carotovorum subsp. brasiliense strain. A plasmid stability assay was conducted to determine whether the plasmid pMP7604 would be maintained within the bacterial cells over a period of at least 21 days in the absence of antibiotic selection because these would be the prevailing conditions during in planta and in situ experiments. Plasmid stability within the mCherry-tagged strain was determined by subculturing daily in the presence (positive control) or absence of tetracycline. Samples from each culture were obtained at 3-day intervals and fluorescence levels were assessed over a period of 22 days. Fluorescence of the mCherry-tagged strain remained high regardless of whether the strain was cultured in the presence or absence of antibiotic pressure (data not shown). To ensure that, indeed, fluorescence was due to viable cells, plate colony counts were determined on NA with or without antibiotic from samples obtained at the 3-day intervals. To evaluate stability, the number of colonies obtained at $1,4,7,15$, and 22 days from subcultured cells of mCherry- $P$. carotovorum subsp. brasiliense cultured in LB broth with or without antibiotic and plated on NA with or without antibiotic, respectively, were compared. The number of colonies obtained when $P$. carotovorum subsp. brasiliense was cultured in the presence of antibiotic was generally the same as when cultured in the absence of antibiotic pressure. However, a reduction of $\approx 2$ and $3.5 \% \mathrm{CFU}$ in the presence of antibiotic was observed for 15 and 22 days, respectively. Based on the similar levels of fluorescence and viable cell counts on NA supplemented with antibiotic, we concluded that the mCherry-tagged strain was relatively stable in the absence of antibiotics and, thus, would suffice for the duration required for all future experiments.

In vitro growth rate of the mCherry-tagged $P$. carotovorum subsp. brasiliense showed no significant difference from that of the wild-type strain. Furthermore, there was no significant difference in maceration ability between $P$. carotovorum subsp. brasiliense and the plasmid-carrying strain. Additionally, no difference was observed between the wild-type and mCherry-tagged strains in virulence on potato stems of a susceptible cultivar (results not included).

Stem-based resistance to $P$. carotovorum subsp. brasiliense in potato ( $S$. tuberosum) cultivars. Four potato cultivars (S. tuberosum Buffelspoort, Mondial, BP1, and Valor) that are commercially planted in South Africa were evaluated for their susceptibility to blackleg disease. In order to compare resistance levels of these cultivars to $P$. carotovorum subsp. brasiliense infection, stems were inoculated with mCherry- $P$. carotovorum subsp. brasiliense and symptom development was recorded daily. Of the four cultivars, BP1 consistently showed no blackleg disease symptoms throughout the duration of the study (21 dpi) in all replicated experiments (Fig. 1). Apart from wounding marks resulting from the stem inoculation procedure, stems remained 
healthy and were comparable with the negative controls. Similar to control plants, leaves showed no signs of yellowing and no wilting of the plant occurred (Fig. 1A). In contrast, the other three cultivars (Mondial, Buffelspoort, and Valor) showed severe blackleg symptoms, identified as ink-like blackening of the stems. Typical blackleg symptoms observed in the case of the three susceptible cultivars are shown in Figure 1B. Blackleg symptoms developed at the POI within the first 2 to $3 \mathrm{dpi}$ and later spread both downward below as well as above the POI. Later stages of disease development included wilting and yellowing of the leaves immediately adjacent to the POI. The average blackleg lesion size was $\approx 15 \mathrm{~cm}$ with no significant difference observed between the three susceptible cultivars. From these results, we concluded that BP1 is relatively more resistant to $P$. carotovorum subsp. brasiliense infection than Valor, Buffelspoort, and Mondial.

Colonization patterns of soil-inoculated $P$. carotovorum subsp. brasiliense in potato plants. In order to establish whether soil-inoculated $P$. carotovorum subsp. brasiliense can infect potato plants through the roots in the absence of wounds, potato roots of a susceptible cultivar (wounded or unwounded) were inoculated with mCherry-tagged $P$. carotovorum subsp. brasiliense cells by soil drench. Subsequently, $P$. carotovorum subsp. brasiliense root colonization was monitored at specific time intervals postinoculation. The presence of mCherry- $P$. carotovorum subsp. brasiliense cells was evaluated visually by CLSM analysis and total CFU were determined. There was no visible mCherry$P$. carotovorum subsp. brasiliense on roots of plants that were inoculated with $\mathrm{MgSO}_{4}$ (controls) (Fig. 2A and B). The presence of $P$. carotovorum subsp. brasiliense cells was observed in the root system of potato plants regardless of whether roots were wounded or not (Fig. 2C to F). Thus, it would appear, from CLSM analysis, that the presence of wounds had no significant effect on bacterial root colonization (Fig. 2). Furthermore, from CLSM data, no evident increase or decrease in mCherry- $P$. carotovorum subsp. brasiliense cells was observed between $12 \mathrm{hpi}$ and 7 dpi of wounded versus unwounded roots. It must be noted that samples were also obtained and CLMS performed at 14 and 21 dpi but these data are not shown because results similar to those in Figure 2 were observed.

CLSM data are not quantitative; hence, viable cell counts were employed for quantitative analysis of colonization. Bacteria were isolated from wounded or unwounded roots to determine total CFU at 12 hpi and 7, 14, and $21 \mathrm{dpi}$. The identity of reisolated tetracycline-resistant colonies was first confirmed by their ability to form pits on CVP and the expected red fluorescence of the mCherry protein. Viable cell counts indicated that, although there was presence of mCherry- $P$. carotovorum subsp. brasiliense in both wounded and unwounded plant roots, the bacterial population levels in the former were eight times higher than the latter at 12 hpi (Fig. 3A). Thus, it would seem that, although wounds are not crucial for entry into the root system, they can significantly accelerate the number of $P$. carotovorum subsp. brasiliense cells entering the root system. Conversely, a proportionate decline of $>10$-fold in the number of bacteria reisolated from both wounded and unwounded roots was observed at time points between 7 and 21 dpi (Fig. 3A; only 21 dpi data shown). Because no additional inoculum was added, it is possible that the observed decline in the amount of mCherry- $P$. carotovorum subsp. brasiliense in the roots was as a result of depleted soil inoculum over time or possible migration of bacteria to aerial stem parts.

To determine possible migration of bacteria from roots into aerial stem parts, stem fragments from soil-inoculated plants with wounded or unwounded roots were harvested and viable CFU were determined. The amount of bacteria reisolated at $12 \mathrm{hpi}$ from stems of plants with wounded roots was significantly higher than that recovered from stems of plants whose roots were still intact (Fig. 3B). Remarkably, after the initial influx of bacteria into the roots and migration into stems, which would have occurred within the first $12 \mathrm{hpi}$, the number of bacteria in the stems generally remained constant for the remainder of the experiment ( 7,14 , and $21 \mathrm{dpi}$ ). Because there was no difference between the three last time points, only results of the final time point are shown in Figure 3B. It is intriguing that, once in the stem, no apparent increase in the $P$. carotovorum subsp. brasiliense population through multiplication was observed. However, this is consistent with the fact that no symptoms were observed in the plants throughout the study. This is perhaps a result of too low $P$. carotovorum subsp. brasiliense inoculum, possibly below quorum-sensing levels and, thus, insufficient levels to reach the critical point required for disease development.

Potato cultivar resistance to $P$. carotovorum subsp. brasiliense correlates with phenotypic appearance and colonization patterns. Prior to inoculation, notable phenotypic differences were observed between the susceptible cultivars and the resistant cultivar, in particular between BP1 (resistant) and Valor (susceptible) (Fig. 4). S. tuberosum BP1 grew vigorously and was dark green in color. The stems were thick, with much darker bases. The generally broad leaves and thicker stems of $S$. tubero-
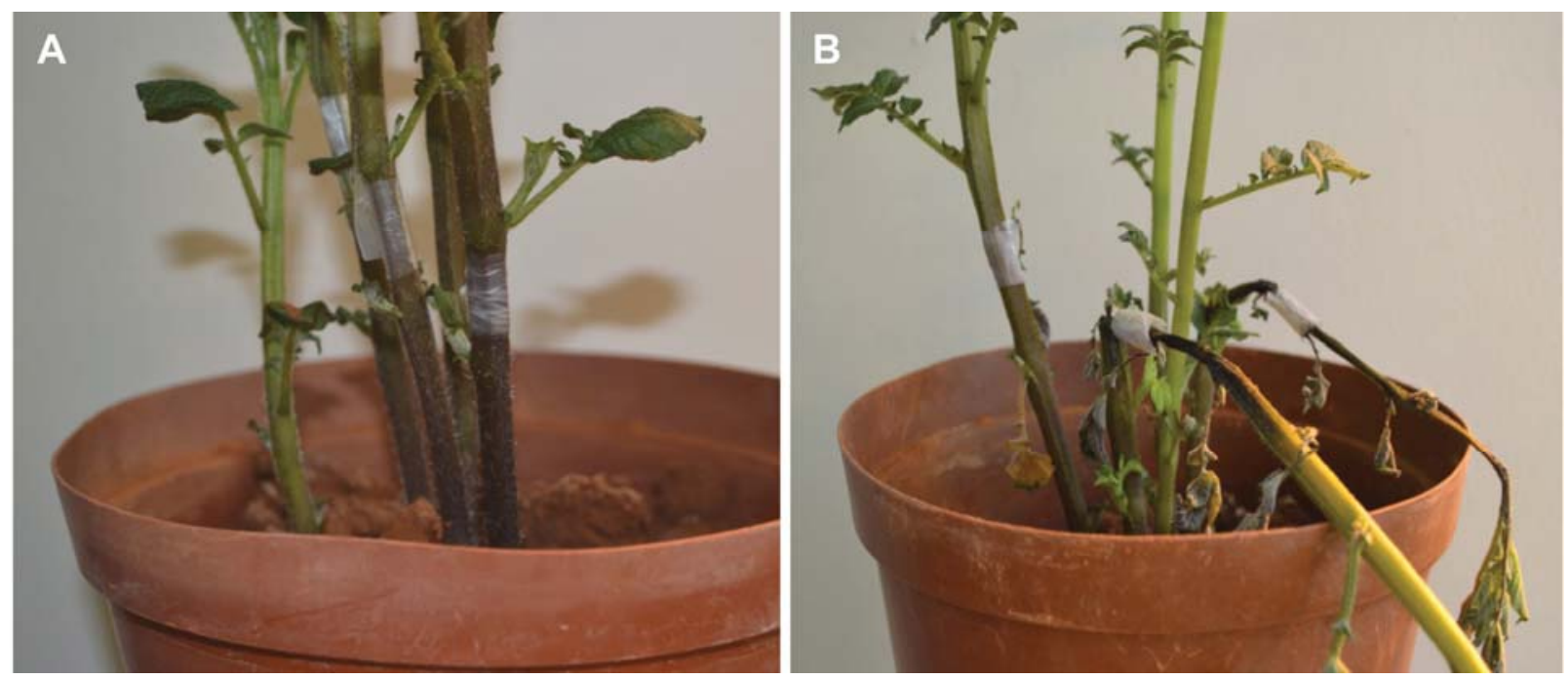

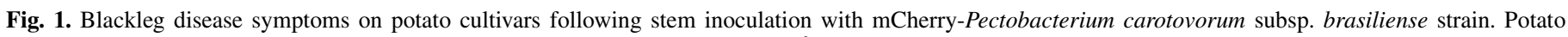

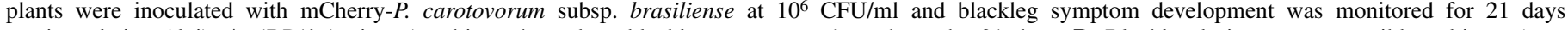

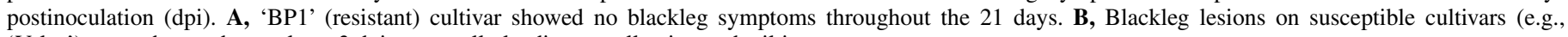
'Valor') were observed as early as $3 \mathrm{dpi}$, eventually leading to yellowing and wilting. 
sum BP1 were further typified by an abundance of tiny hairs, especially at a younger age (Fig. 4A, C, F, and G). The opposite was true with $S$. tuberosum Valor, which had a delicate, almost yellow-green appearance. The stems and leaves were typically thinner, smaller, and more delicate in appearance, with fewer hairs (Fig. 4B, D, E, and H).

Based on observed phenotypic differences between resistant and susceptible cultivars, we hypothesized that pre-existing

\section{wounded}

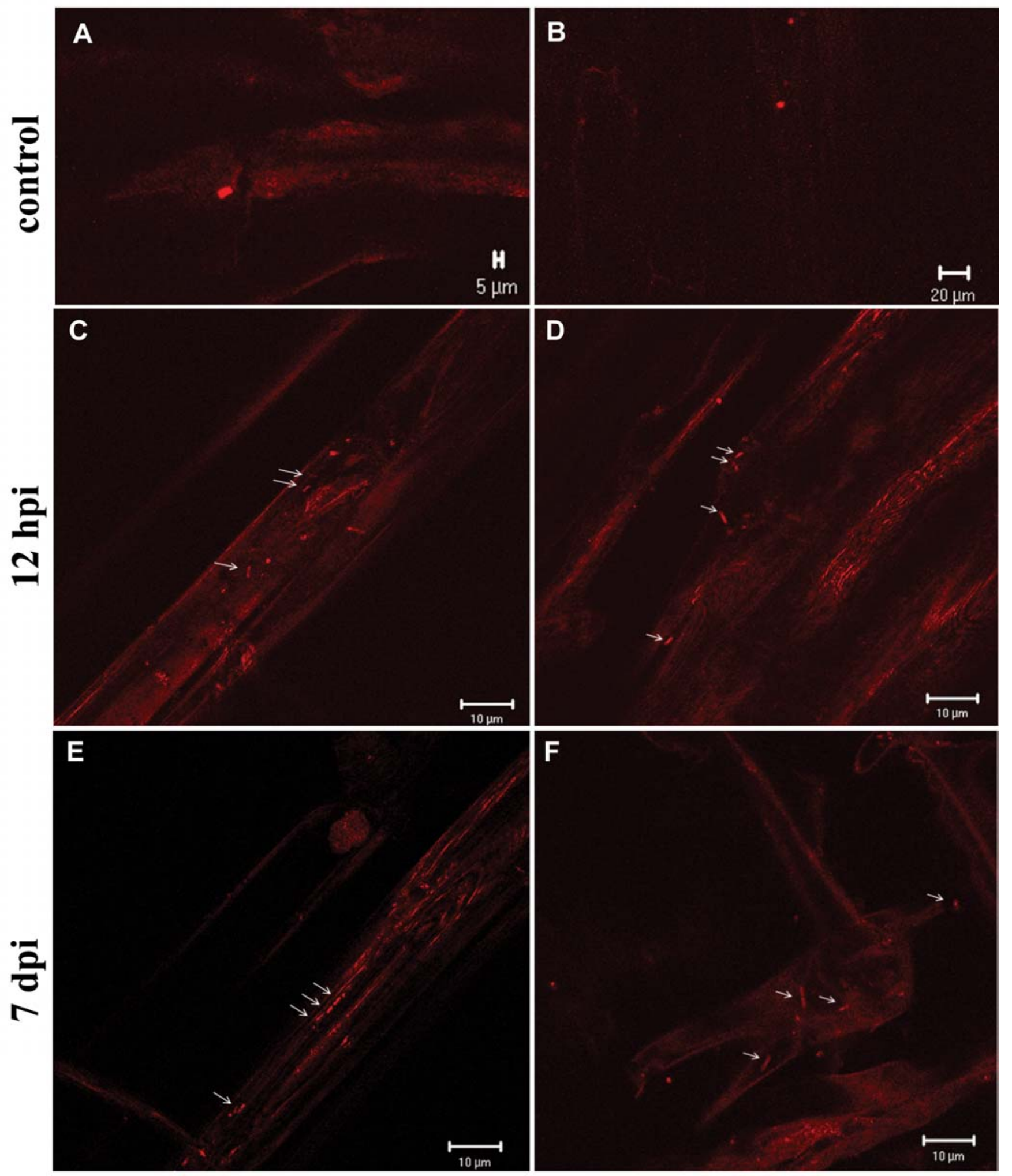

Fig. 2. Colonization of susceptible potato plant roots by mCherry-tagged Pectobacterium carotovorum subsp. brasiliense cells (indicated by the arrows) observed with confocal laser-scanning microscopy. $\mathbf{A}$ and $\mathbf{B}$, Control $\mathbf{M g S O}_{4}$-inoculated plants. $\mathbf{C}$ and $\mathbf{D}$, mCherry-P. carotovorum subsp. brasiliense soil-drenchinoculated roots at $12 \mathrm{~h}$ postinoculation (hpi) and $\mathbf{E}$ and $\mathbf{F}, 7$ days postinoculation (dpi). Wounded (A, C, and E) or unwounded (B, D, and F) potato plant roots were inoculated by immersion (30\%) into $200 \mathrm{ml}$ of a bacterial suspension $\left(10^{8} \mathrm{CFU} / \mathrm{ml}\right)$ overnight. 
structural or biochemical differences between $S$. tuberosum BP1 and Valor may be limiting migration of $P$. carotovorum subsp. brasiliense in the resistant cultivar and, thus, limit or prevent the bacteria from causing an infection. Thus, to test this hypothesis, 6-week-old plants of the two cultivars, one susceptible (Valor) and one resistant (BP1), were inoculated with mCherry- $P$. carotovorum subsp. brasiliense and samples obtained at $6 \mathrm{~cm}$ below and above the POI. Similar to our previous results evaluating resistance levels, there was no symptom development in $S$. tuberosum BP1 whereas Valor developed typical blackleg symptom as early as 3 dpi. However, even though three stems per plant were inoculated, typically not all the stems developed symptoms. Thus, for our colonization studies, only asymptomatic inoculated stems of both the susceptible and resistant cultivar were chosen. The choice of asymptomatic stems over symptomatic in the susceptible cultivar was influenced by massive tissue maceration and subsequent collapse associated with blackleg development, which would have made CLSM studies impossible.

In order to monitor and quantify the amount of bacteria in each cultivar at different time points, samples were obtained from asymptomatic stems of the susceptible and resistant plants at $6 \mathrm{~cm}$ below the POI. Contrary to our hypothesis, the mCherry-P. carotovorum subsp. brasiliense strain migrated and colonized stems of both cultivars equally at $6 \mathrm{~cm}$ below the POI (Fig. 5). We also sampled at $6 \mathrm{~cm}$ above the POI and observed no differences in the amount of $P$. carotovorum subsp. brasiliense sampled for the susceptible compared with the resistant cultivar (data not shown). Even though significant differences in symptom development were observed between the two potato cultivars, it was noteworthy that the numbers of bacteria isolated from asymptomatic stems at most time points were equally high. For this reason, BP1 was identified as tolerant and not resistant to $P$. carotovorum subsp. brasiliense infection, as previously determined (Fig. 5). The control plants remained healthy for the duration of the study and, as can be expected, no mCherry- $P$. carotovorum subsp. brasiliense cells could be reisolated from these plants.

To compare the extent to which the mCherry- $P$. carotovorum subsp. brasiliense cells migrated below POI between Valor and BP1, the mother tubers of stem-inoculated plants were harvested at the end of the experiment. In all, $\approx 75 \%$ of mother tubers of the susceptible cultivar (Valor) showed signs of soft rot symptoms, observed as a sogginess and collapse of the potato tuber tissue. In contrast, the mother tubers of the tolerant (BP1) cultivar showed no soft rot symptoms. To eliminate the possibility that the observed soft rot symptoms in the susceptible cultivar were due to latent infections of the mother tubers, bacteria were reisolated from the harvested mother tubers of both cultivars and identified as mCherry- $P$. carotovorum subsp. brasiliense by plating on CVP media supplemented with tetracycline. Hence, reisolated bacteria were shown to be tetracycline-resistant, pit-forming bacteria and

A

mCherry-Pcb in roots

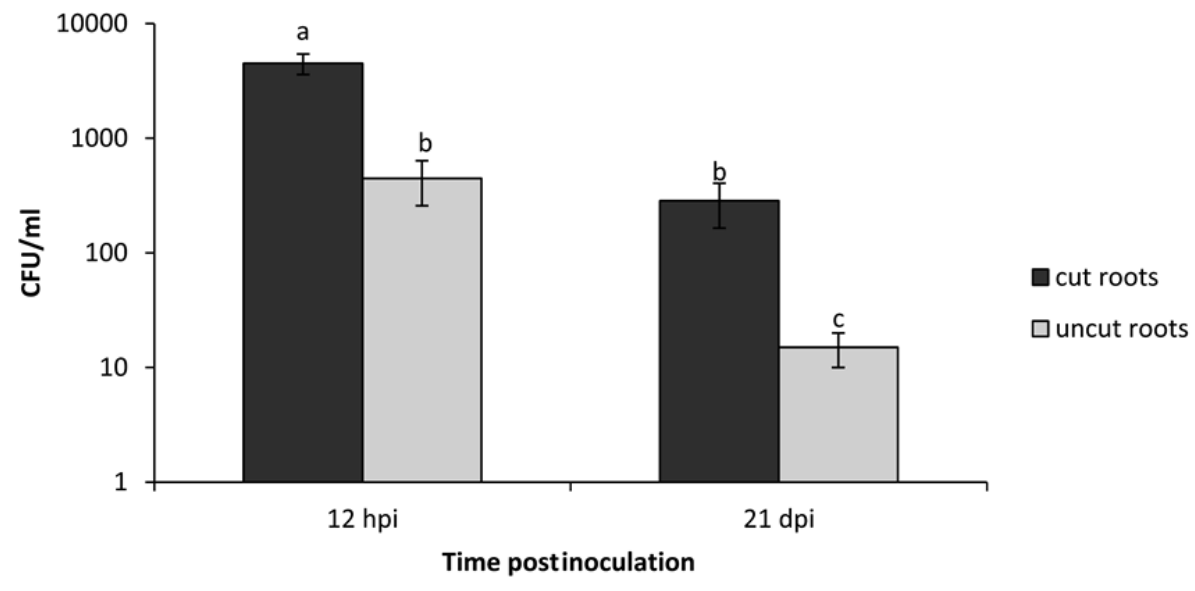

B

mCherry-Pcb in stems of root inoculated plants

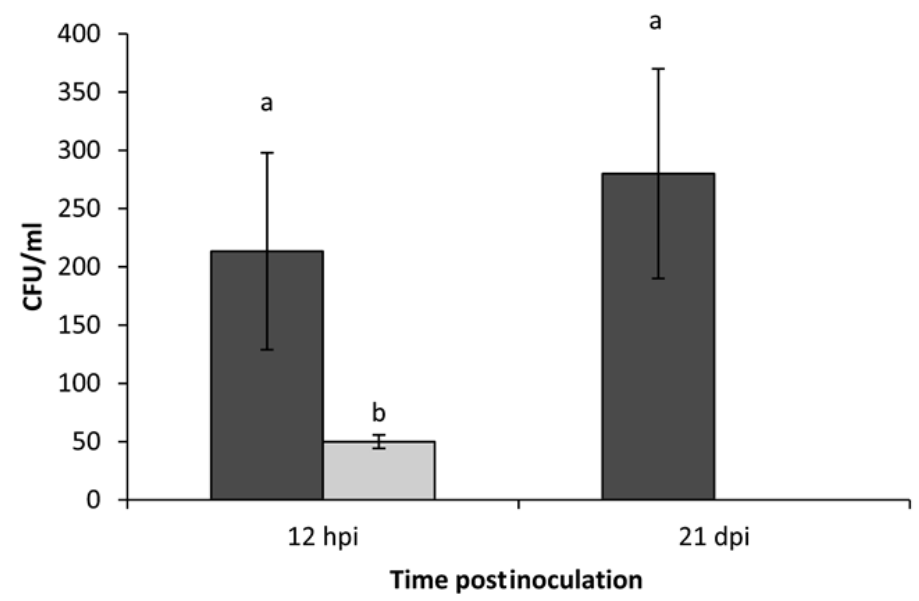

$\square$ cut roots

$\square$ uncut roots

Fig. 3. Colonization of susceptible potato plants roots and stems inoculated with mCherry-Pectobacterium carotovorum subsp. brasiliense strain by soil-drench. A, Roots and $\mathbf{B}, 2$-cm-thick stem fragments at $10 \mathrm{~cm}$ above the soil level were harvested from wounded and unwounded plants following inoculation with $200 \mathrm{ml}$ of suspension $\left(10^{8} \mathrm{CFU} / \mathrm{ml}\right)$. Samples were harvested at $12 \mathrm{~h}$ postinoculation (hpi) and 7, 14, and 21 days postinoculation (dpi) and total CFU/ml was determined. The experiment was repeated twice and the error bars represent standard error of the mean. Each bar represents a mean of three independent replicates (12 plants per experiment) and bars; the same letters are not significantly different $(P=0.05)$. 
fluoresced red under CLSM, suggesting that these were indeed the mCherry- $P$. carotovorum subsp. brasiliense inoculum initially inoculated into the stems. The same was true with bacterial cells isolated from the tubers of the resistant (BP1) potato cultivar. However, the bacterial numbers harvested from these were very low, consistent with the lack of soft rot symptoms observed. From these results, we concluded that $P$. carotovorum subsp. brasiliense is able to translocate from infected stems of the susceptible cultivar downward and into the mother tubers but, in the case of the tolerant cultivar, this downward translocation into mother tubers was limited, possibly at the junction between the stem and tuber.

Vascular tissue colonization. Colonization patterns of mCherry$P$. carotovorum subsp. brasiliense in stems was qualitatively analyzed with CLSM to visually evaluate and compare its distribution within the susceptible and tolerant potato cultivars. Cross sections of the stem ( $2 \mathrm{~cm}$ thick) were sampled from inoculated but asymptomatic stems of Valor and BP1, $6 \mathrm{~cm}$ above and below the POI. These stem fragments were prepared for microscopy to localize $P$. carotovorum subsp. brasiliense within plant tissues.

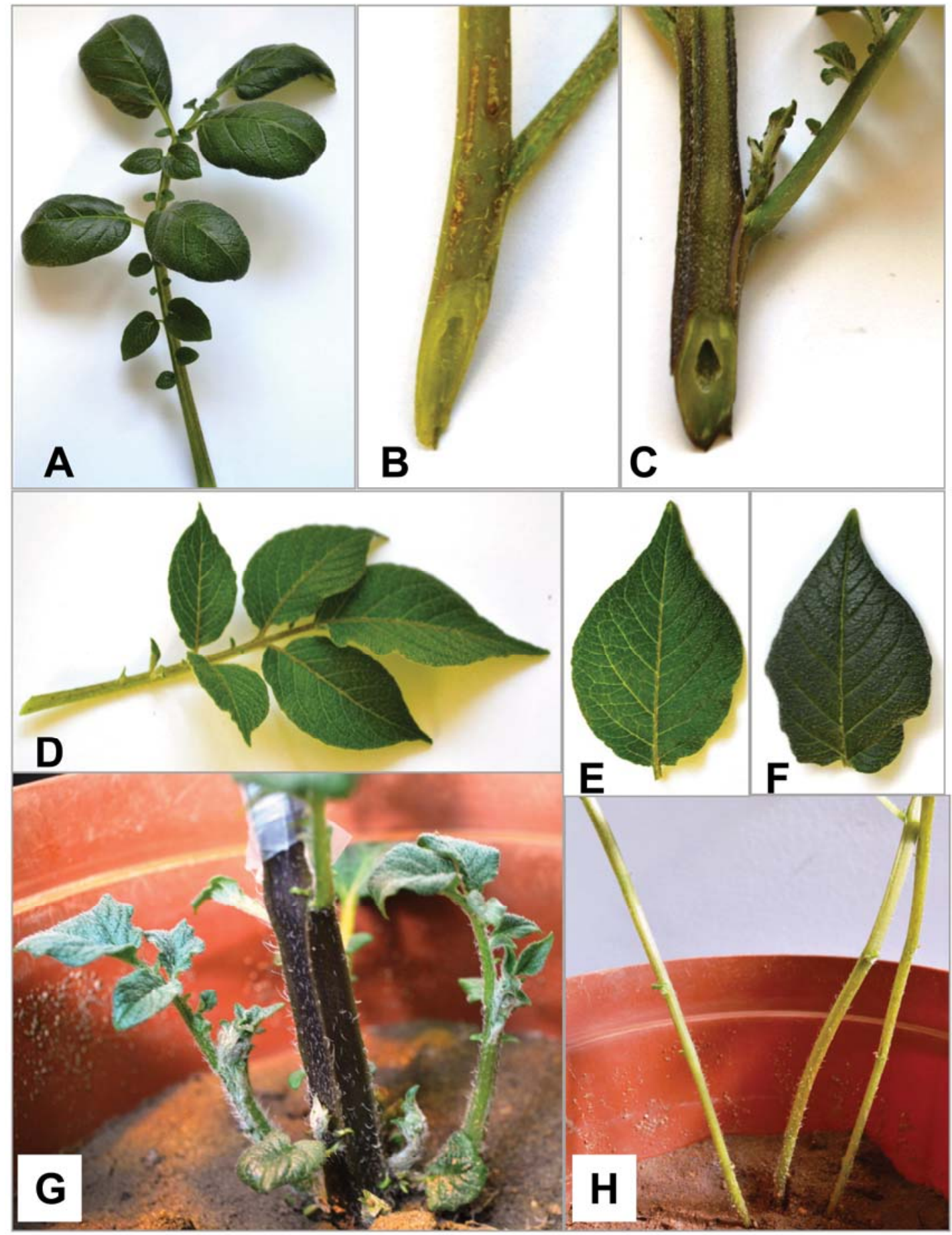

Fig. 4. Phenotypic differences between 'Valor' (susceptible) and 'BP1' (resistant) potato cultivar at 4 to 5 weeks old. A, C, F, and G, Resistant BP1 had a stronger appearance and was darker in color. $\mathbf{C}$ and $\mathbf{G}$, Stems of the resistant cultivar were thick, with much darker bases, and $\mathbf{A}$ and $\mathbf{F}$, leaves were broader, thicker, and darker than the susceptible cultivar. G, Leaves and stems of the resistant cultivar typically had many tiny hairs, especially at a younger stage. B, D, E, and $\mathbf{H}$, Susceptible cultivars (e.g., Valor) had a generally delicate structure with an almost yellow-green appearance and $\mathbf{H}$, the stems and leaves were thinner and smaller, respectively, with fewer hairs. 
Mock-inoculated plant tissues of the susceptible cultivar (Valor) illuminated at a wavelength of $560 \mathrm{~nm}$ and above were typically observed as dim autofluorescing patches (Fig. 6A) and representative xylem vessels identified by their roughly octagonshaped lignified cell walls (Fig. 6A, indicated by arrows). When the same representative mock-inoculated stem section was illuminated at a wavelength of 560 to $615 \mathrm{~nm}$ (wavelength for mCherry fluorescence), very little plant auto fluorescence was observed (Fig. 6B). Thus, all mCherry-P. carotovorum subsp. brasilienseinoculated plants were viewed at a wavelength of 560 to $615 \mathrm{~nm}$. In the earlier inoculation time points $(4 \mathrm{dpi})$, sampled stem sections of the susceptible cultivar could only be viewed at a higher magnification $(\times 63)$. This is possibly because of the low levels of colonizing bacteria in planta, particularly at this early time point. Initially, stem cross sections were viewed under whitelight illumination and bacterial cells were observed within individual cells of the xylem tissue (Fig. 6C and D). When switching to UV, these bacterial cells fluoresced red (confirming their identity as mCherry- $P$. carotovorum subsp. brasiliense) and often appeared to be forming "biofilm-like" aggregates (Fig. 6C to E). In later time points ( 4 dpi onward), bacteria could often be easily localized as biofilm-like $P$. carotovorum subsp. brasiliense cell aggregates lining the xylem tissue (Fig. 6E to $\mathrm{G}$ ) at the lower magnification $(\times 10)$. In samples obtained at the final time point (21 dpi), the mCherry- $P$. carotovorum subsp. brasiliense cells appeared to have multiplied to such high numbers that they were able to colonize the xylem vessels to points of occlusion (Fig. $6 \mathrm{H})$. However, in general, the number of colonized and occluded xylem vessels remained minimal. This minimal occlusion may be attributed to the fact that only asymptomatic stems were sampled. Due to the minimal occlusion observed, it may be that there was less restriction of water flow in these asymptomatic stems and, therefore, no wilting symptoms were observed (34). Thus, we speculate that, in symptomatic stems, there may have been more occlusion of xylem vessels to account for the observed wilting symptoms on the diseased (blackleg) stems.

Interesting but contrasting differences were noted in the colonization patterns of mCherry- $P$. carotovorum subsp. brasiliense on the tolerant compared with susceptible cultivar. At low magnification $(\times 10)$, no bacterial colonization was evident in the tolerant cultivar at all sampled time points. However, at higher magnification $(\times 63)$, high populations of mCherry- $P$. carotovorum subsp. brasiliense cells were observed within the same sampled plant (BP1) material (4 to $21 \mathrm{dpi}$ ). Contrary to the susceptible cultivar where the bacteria were observed forming biofilm-like aggregates lining the xylem tissue, in the tolerant cultivar, bacterial cells were generally observed as planktonic or single free-swimming cells (Fig. 6I). Furthermore, unlike in the susceptible cultivar, where colonization was clearly localized in the xylem tissue, the mCherry- $P$. carotovorum subsp. brasiliense cells in the tolerant cultivar were more dispersed.

\section{DISCUSSION}

In this study, $P$. carotovorum subsp. brasiliense strain 1692 was transformed with plasmid pMP7604 which, in addition to the tetracycline resistance gene, harbors the red $m$ Cherry gene. Transformants were confirmed as $P$. carotovorum subsp. brasiliense by plating on CVP medium and IGS-specific PCR with the primers BR1f/L1r, which are species specific for $P$. carotovorum subsp. brasiliense $(18,24)$. These pMP7604 plasmid-carrying $P$. carotovorum subsp. brasiliense cells were finally confirmed to efficiently express mCherry by CLSM. The mCherry plasmid was shown to be stable for 22 days; thus, it was concluded that the plasmid is fairly stable for the required duration of all future studies.

Better understanding of $P$. carotovorum subsp. brasiliense pathogenesis can lead to identification of critical target points to successfully circumvent the spread of Pectobacterium spp. and development of appropriate control measures (3). Second to infected seed tubers, soil is arguably an important source of inoculum for Dickeya spp. (12,34). However, as noted by Nabhan et al. (31), this has not been established for most Pectobacterium spp. Hence, we conducted a study to determine whether soilborne $P$. carotovorum subsp. brasiliense can infect unwounded roots of a highly susceptible potato cultivar. The mCherry-tagged $P$.

\section{mCherry-Pcb colonization in stems of different potato cultivars}

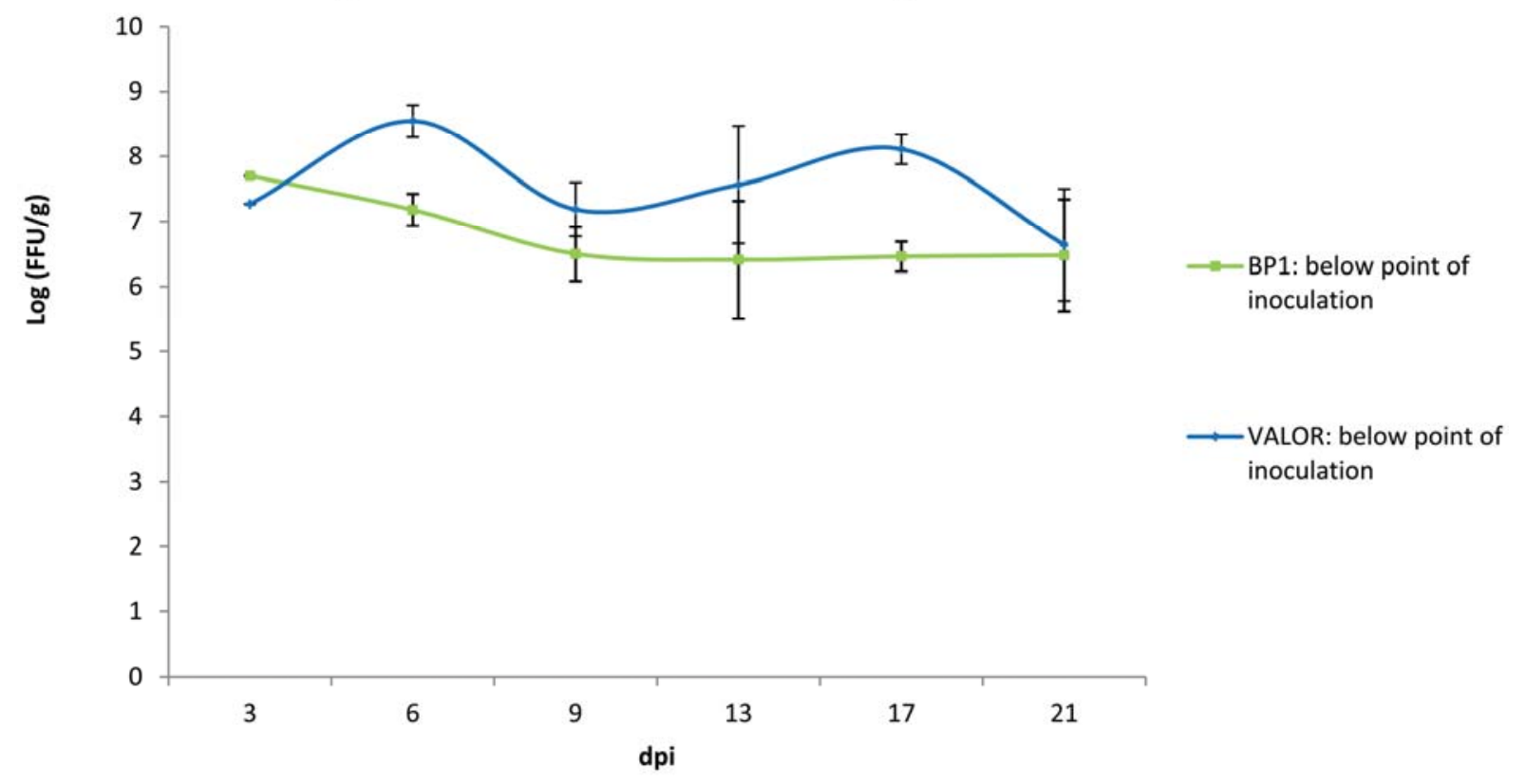

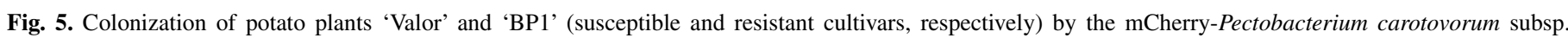

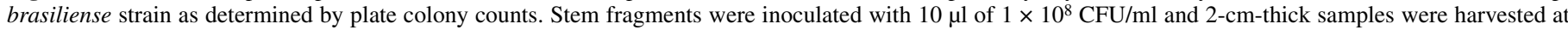

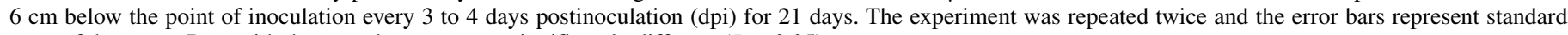
error of the mean. Bars with the same letters are not significantly different $(P=0.05)$. 
carotovorum subsp. brasiliense strain infected potato plant roots in the presence or absence of wounds, albeit at very low levels for the latter. This might suggest that bacterial entry into roots occurs naturally but not in amounts high enough to trigger symptom development. The observed $P$. carotovorum subsp. brasiliense behavior is similar to that observed for most soilborne pathogens, such as $D$. solani biovar 3, which is able to gain entrance into the root system of potato plants in the absence of wounds (12). The
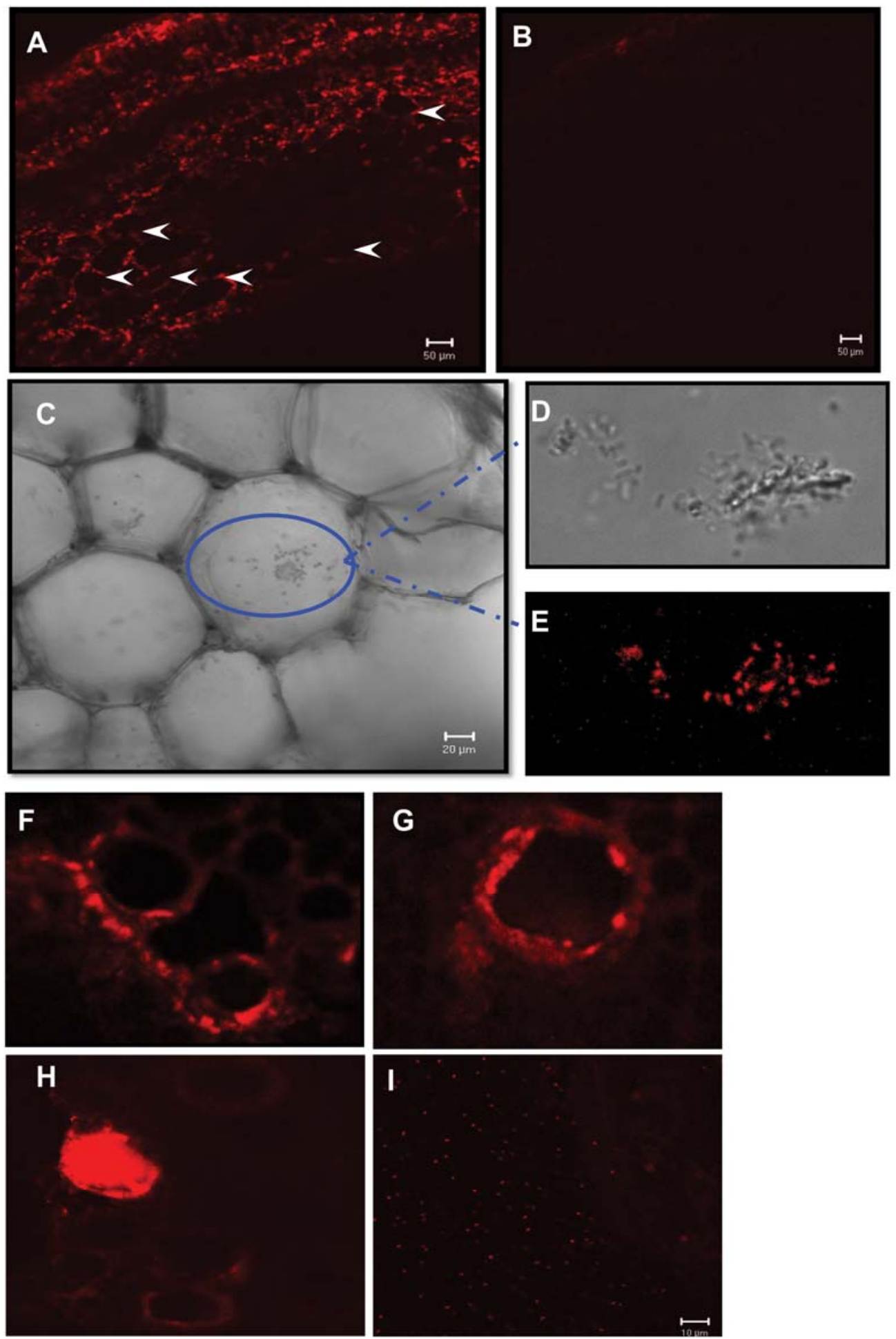

Fig. 6. Confocal laser-scanning microscopy micrographs showing stem tissues of potato plants colonized by mCherry-Pectobacterium carotovorum subsp. brasiliense cells. A, Illustration of the observed fluorescence when stem cross-sections are illuminated with a light pass of $560 \mathrm{~nm}$ and above. The resulting fluorescence represents the plant's autofluorescence and mCherry-P. carotovorum subsp. brasiliense. B, Representative mock-inoculated control illuminated at a wavelength of 560 to $615 \mathrm{~nm}$ showing only the mCherry-P. carotovorum subsp. brasiliense fluorescence without plant autofluorescence. No fluorescence was observed in this $\mathrm{MgSO}_{4}$-negative control, indicating the absence of the mCherry AFP. Cross-sections of stems of the susceptible potato 'Valor' sampled below the point of inoculation were illuminated with $\mathbf{C}$, white light and bacterial cells localized inside individual xylem vessels. D, Single xylem vessel, magnified to highlight colonizing bacteria. E, Subsequent UV irradiation at a wavelength of 560 to $615 \mathrm{~nm}$ revealed aggregates of fluorescent mCherry-P. carotovorum subsp. brasiliense cells, indicating the identity of the bacterial cells located within individual xylem vessels. $\mathbf{F}, \mathbf{G}$, and $\mathbf{H}$, P. carotovorum subsp. brasiliense cells could be seen lining and colonizing the xylem vessels in the form of biofilm-like colonies at $\times 10$ magnification. I, The mCherry-P. carotovorum subsp. brasiliense cells within the tolerant potato 'BP1' at $\times 63$ magnification. 
low levels of $P$. carotovorum subsp. brasiliense invading intact plant roots my indicate that it is potentially important as a soilborne inoculum. However, the full risk of a soilborne P. carotovorum subsp. brasiliense inoculum to the potato industry will need to be established further because it is dependent on factors such as survival in soil. Although wounds were not required for entry, their presence appeared to accelerate the initial stages of $P$. carotovorum subsp. brasiliense uptake via roots. This can be expected due to the increased surface absorption area on roots that were cut (wounded) compared with those which were not.

In both wounded and unwounded plants, significantly higher levels of $P$. carotovorum subsp. brasiliense were translocated into the roots during the first $12 \mathrm{~h}$ of inoculation (Fig. 3A). However, following this initial influx into roots, a noticeable decline (10fold or more) in mCherry-P. carotovorum subsp. brasiliense cells colonizing both wounded and unwounded roots was observed. This decline could be due to the fact that, after the initial inoculation of mCherry-P. carotovorum subsp. brasiliense cells in the soil, no additional inoculum was added and, therefore, there would have been a lack of free $P$. carotovorum subsp. brasiliense inoculum in the soil. Additionally, it is possible that, through the transpiration process, most of the bacteria would have been translocated upward into stem tissue. This upward migration of bacteria via the xylem was confirmed by evaluating the amount of $P$. carotovorum subsp. brasiliense in stem segments obtained at $10 \mathrm{~cm}$ above the soil level. However, overall, the population levels of $P$. carotovorum subsp. brasiliense isolated from both the roots and stems of the root-inoculated plants were generally low and failed to proliferate to disease-causing levels (Fig. 3A and B). This also coincided with the fact that there were no blackleg symptoms on plants. Similarly, Czajkowski et al. (11) also noted a lack of blackleg symptom development and low bacterial levels on green fluorescent protein-tagged Dickeya spp. biovar 3 soilinoculated potato roots.

The soft rot-blackleg/wilt disease complex is of economic importance for the potato industry worldwide. However, there is not much literature concerning the control of SRE by means of resistance and this may be linked to factors such as poor correlation between tuber soft rot and blackleg resistance $(1,13,16$, 19,35). Although several studies have addressed various aspects of tuber resistance, even fewer studies have investigated stembased resistance mechanisms. Ngadze et al. (32) previously evaluated tuber based-resistance levels of various commercial South African potato cultivars to soft rot caused by $P$. atrosepticum, $P$. carotovorum subsp. brasiliense, and $D$. dadantii. In the current study, we evaluated stem-based resistance of four commercially planted South African potato cultivars against blackleg disease. Of the four cultivars evaluated, three were highly susceptible and the fourth, S. tuberosum BP1, did not develop blackleg symptoms and, thus, was initially considered to be resistant but later referred to as tolerant to $P$. carotovorum subsp. brasiliense infection. We noted very clear phenotypic differences between the tolerant and susceptible cultivars, particularly between $S$. tuberosum BP1 (tolerant) and Valor (susceptible) (Fig. 4). Marquez-Villavicencio et al. (29) previously demonstrated a link between potato tuber physiological factors such as tuber size, maturity, and susceptibility. Hence, we speculated that, in the tolerant cultivar, bacteria would be confined and unable to move away from the POI whereas there would be free movement of bacteria in the susceptible cultivar leading to observed blackleg symptoms. To our surprise, there was no significant difference in the amounts of bacteria reisolated from the two cultivars at $6 \mathrm{~cm}$ above or below the POI. According to Clarke (10), resistance strategies limit infection whereas tolerance strategies offset or reduce the consequences of disease without necessarily limiting infection. Hence, the equal bacterial populations observed between the two cultivars led us to conclude that $\mathrm{BP} 1$ is tolerant to $P$. carotovorum subsp. brasiliense and not resistant as we had previously deter- mined. Second, this suggested that, in both cultivars, bacteria were able to migrate up- or downward without any apparent restriction. The only notable cultivar difference observed was in the amount of bacteria isolated from tubers of stem-inoculated plants. In the susceptible cultivar, $75 \%$ of the tubers had severe soft rot symptoms and bacteria reisolated from these tubers were confirmed as the initial inoculum by ability to form cavities on CVP and tetracycline resistance. In the resistant cultivar, no rotting symptoms were observed on the tubers; however, a small amount of mCherry- $P$. carotovorum subsp. brasiliense cells was isolated. This would suggest that the base of the stems in this cultivar acts as a barrier, preventing movement of bacteria between the stem and underground tubers. Indeed, anatomical features of stem tissues such as lignifications have been shown to act as barriers at the junction between the mother tuber and emerging stems and may subsequently hinder bacterial migration at varying degrees in different potato cultivars $(1,2)$.

CLSM was used to compare stem ultrastructural colonization patterns of mCherry- $P$. carotovorum subsp. brasiliense in the susceptible and tolerant cultivars. We noted that, in the susceptible cultivar, $P$. carotovorum subsp. brasiliense tended to colonize the xylem vessels, occurring as either clusters or biofilm-like aggregates in the middle of the xylem or lining the walls of xylem tissues. In some vascular tissues, these aggregates had developed to the point of occluding entire xylem vessels. However, in general, only a few of the vessels were completely occluded. We ascribed this to the choice of asymptomatic stems rather than stems that developed symptoms. Thus, it is likely that, in symptomatic stems, more xylem vessels would be occluded, leading to reduced water flow, wilting, and typical blackleg symptoms. These biofilm-like colonies have also been reported with the gram-positive bacterium Clavibacter michiganensis subsp. sepedonicus, which forms bacterial aggregates embedded in an exopolymetric matrix and attaches to the walls of xylem vessels of potato plants $(7,28)$. Colonization of the xylem vessels is also central in the systemic spread of gram-negative phytopathogens such as Erwinia amylovora $(4,26)$. Furthermore, D. solani, a member of the SRE, has also been shown to utilize xylem vessels to systemically colonize potato plant tissues following root, stem, and leaf infection. The bacteria is reported to colonize within and between parenchyma cells in roots, xylem vessels, and protoxylem cells in stems and stolons, as well as the stolon ends of progeny tubers (11).

Intriguingly, $P$. carotovorum subsp. brasiliense colonization of the tolerant cultivar was quite the opposite of what was observed in the susceptible cultivar. In the tolerant potato cultivar (BP1), mCherry- $P$. carotovorum subsp. brasiliense cells were free swimming or planktonic, unlike the biofilm-like colonies observed previously in the susceptible cultivar. This was contrary to our initial hypothesis that structural defenses likely limit movement of $P$. carotovorum subsp. brasiliense in the resistant or tolerant cultivar. From these observations, it would rather seem that, in the susceptible cultivar, $P$. carotovorum subsp. brasiliense is able to form aggregates or biofilm-like colonies and this facilitates the development of disease. On the other hand, in the tolerant cultivar, $P$. carotovorum subsp. brasiliense is unable to aggregate and, hence, it is unable to cause disease. The role of biofilms in plant-microbe interactions is well documented (14, 37). During the colonization of xylem vessel by many phytopathogens, biofilm development has been shown to play a key role and is instrumental in pathogen density-dependent communication, establishment, and expansion followed by disease propagation and, thus, pathogenicity $(15,20,23,37)$. Biofilms are favored during plant colonization because of their resilience, compared with planktonic bacteria. This is thought to be a consequence of the biofilm's structural and population heterogeneity, which provides a diverse population that can resist diverse challenges such as plant defenses $(17,23)$. In the tolerant cultivar, 
P. carotovorum subsp. brasiliense was unable to form these aggregates; therefore, we suggest that this inability to form aggregates may account for the observed tolerant response and failure to cause disease symptoms in the tolerant cultivar. It is likely that inability to form these biofilm-like structures is due to responses inflicted on the pathogen by the tolerant cultivar which limit bacterial virulence without necessarily affecting multiplication. Several factors to this effect have been reported; for example, Prithiviraj et al. (36) demonstrated that the Arabidopsis systemic plant defense signaling molecule, salicylic acid, suppresses Pseudomonas aeruginosa virulence genes such as those involved in attachment and biofilm formation without limiting bacterial growth. Additionally, Pérez-Mendosa et al. (33) showed that in vitro biofilm formation in $P$. atrosepticum is activated and elevated by another signaling molecule, c-di-GMP. These authors suggested that, in the environment, it is possible that c-di-GMP modulate biofilm formation in $P$. atrosepticum as a response to asyet-unidentified plant signals in the environment. Hence, the actual nature of cultivar tolerance response mechanisms leading to suppression of biofilm formation by $P$. carotovorum subsp. brasiliense will need to be further established.

\section{ACKNOWLEDGMENTS}

This project was funded by the National Research Foundation (Thuthuka Programme) of South Africa. The mCherry plasmid was kindly provided by E. L. Lagendijk, Institute of Biology Leiden, Leiden University. We thank A. N. Hall and S L. Ungerer (Microscopy and Microanalysis, University of Pretoria) for assistance with microscopy.

\section{LITERATURE CITED}

1. Abenthum, K., Hildenbrand, S., and Ninnemann, H. 1995. Elicitation and accumulation of phytoalexins in stems, stolons and roots of Erwiniainfected potato plants. Physiol. Mol. Plant Pathol. 46:349-359.

2. Allefs, S. J. H. M., Florack, D. E. A., Hoogendoorn, C., and Stiekema, W. J. 1995. Erwinia soft rot resistance of potato cultivars transformed with a gene construct coding for antimicrobial peptide cecropin B is not altered. Am. Potato J. 72:437-445.

3. Allen, C., Bent, A., and Charkowski, A. O. 2009. Underexplored niches in research on plant pathogenic bacteria. Plant Physiol. 150:1631-1637.

4. Burse, A., Weingart, H., and Ullrich, M. S. 2004. NorM, an Erwinia amylovora multidrug efflux pump involved in in vitro competition with other epiphytic bacteria. Appl. Environ. Microbiol. 70:693-703.

5. Cappaert, M., Powelson, M. L., Franc. G. D., and Harison, M. D. 1988. Irrigation water as a source of inoculum of soft rot erwinias for aerial stem rot of potatoes. Phytopathology 78:1668-1872.

6. Carputo, D., Cardi, T., Speggiorin, M., Zoina, A., and Frusciante, L. 1997. Resistance to blackleg and tuber soft rot in sexual and somatic interspecific hybrids with different genetic background. Am. J. Potato Res. 74:161-172.

7. Chalupowicz, L., Zellermann, E. M., Fluegel, M., Dror, O., Eichenlaub, R., Gartemann, K. H., Savidor, A., Sessa, G., Iraki, N., Barash, I., and Manulis-Sasson, S. 2012. Colonization and movement of GFP-labeled Clavibacter michiganensis subsp. michiganensis during tomato infection. Phytopathology 102:23-31.

8. Charkowski, A. O. 2009. Decaying signals: Will understanding bacterialplant communications lead to control of soft rot? Curr. Opin. Biotechnol. 20:178-184.

9. Charkowski, A. O., Blanco, C., Condemine, G., Expert, D., Franza, T., Hayes, C., Hugouvieux-Cotte-Pattat, N., Solanilla, E. L., Low, D., Moleleki, L., Pirhonen, M., Palenzuela, P. R., Francisco, M. S., Toth, I., Tsuyumu, S., van der Waals, J., van der Wolf, J., Gijsegem, F. V., Yang, C.-H., and Yedidia, I. 2012. The role of secretion systems and small molecules in soft rot enterobacteriaceae pathogenicity. Annu. Rev. Phytopathol. 50:425-449.

10. Clarke D. D. 1986. Tolerance of parasites and disease of plants and its significance to host pathogen interaction. Adv. Plant Pathol. 5:161-197.

11. Czajkowski, R., de Boer, W. J., van Veen, J. A., and van der Wolf, J. M. 2010. Downward vascular translocation of a green fluorescent proteintagged strain of Dickeya sp. (biovar 3) from stem and leaf inoculation sites on potato. Phytopathology 100:1128-1137.

12. Czajkowski, R., de Boer, W. J., Velvis, H., and van der Wolf, J. M. 2010. Systemic Colonization of potato plants by a soilborne green fluorescent protein-tagged strain of Dickeya sp. biovar 3. Phytopathology 100:134-142.
13. Czajkowski, R., Perombelon, M. C. M., van Veen, J. A., and van der Wolf, J. M. 2012. Control of blackleg and tuber soft rot of potato caused by Pectobacterium and Dickeya species: A review. Plant Pathol. 60:9991013.

14. Danhorne, T., and Fuqua, C. 2007. Biofilm formation by plant-associated bacteria. Annu. Rev. Microbiol. 61:401-422.

15. Davey, M. E., and O'Toole, G. A. 2000. Microbial biofilms: From ecology to molecular genetics. Microbiol. Mol. Biol. Rev. 64:847-867.

16. Dean, R., and Kuc, J. 1987. Rapid lignification in response to wounding and infection as a mechanism for induced systemic protection in cucumber. Physiol. Mol. Plant Pathol. 31:69-81.

17. Denny, T. P. 1995. Involvement of bacterial polysaccharides in plant pathogenesis. Annu. Rev. Phytopathol. 33:173-197.

18. Duarte, V., De Boer, S. H., Ward, L. J., and de Oliviera, A. M. R. 2004. Characterization of atypical Erwinia carotovora strains causing blackleg of potato in Brazil. J. Appl. Microbiol. 96:535-545.

19. Fock, I., Collonnier, C., Luisetti, J., Purwito, A., Souvannavong, V., Vedel, F., Servaes, A., Ambroise, A., Kodja, H., Ducreux, G., and Sihachakr, D. 2001. Use of Solanum stenotomum for introduction of resistance to bacterial wilt in somatic hybrids of potato. Plant Physiol. Biochem. 39:899908.

20. Fuqua, C., and Greenberg, E. P. 2002. Listening in on bacteria: Acylhomoserine lactone signalling. Nat. Rev. Mol. Cell Biol. 3:685-695.

21. Glasner, J. D., Marquez-Villavicencio, M., Kim, H.-S., Jahn, C. E., Ma, B., Biehl, B. S., Rissman, A. I., Mole, B., Yi, X., Yang, C.-H., Dangl, J. L., Grant, S. R., Perna, N. T., and Charkowski, A. O. 2008. Nichespecificity and the variable fraction of the Pectobacterium pan genome. Mol. Plant-Microbe Interact. 21:1549-1560.

22. Grenier, A.-M., Duport, G., Peges, S., Condemine, G., and Rahbe, Y. 2006. The phytopathogen Dickeya dedantii (Erwinia chrysenthemi 3937) is a pathogen of the pea aphid. Appl. Environ. Microbiol. 72:1956-1965.

23. Harrison, J., Turner, R., Marques, L., and Ceri, H. 2005. Biofilms: A new understanding of these microbial communities is driving a revolution that may transform the science of microbiology. Am. Sci. 93:508-515.

24. Hyman, L. J., Sullivan, L., Toth, I. K., and Perombelon, M. C. M. 2002. Modified crystal violet pectate medium (CVP) based on a new polypectate source (Slendid) for the detection and isolation of soft rot erwinias. Potato Res. 44:265-270.

25. Klopper, J. W., Brewer, J. W., and Harrison, M. D. 1981. Insect transmission of Erwinia carotovora var. carotovora and Erwinia carotovora var. atroseptica to potato plants in the field. Am. J. Potato Res. 58:165-175.

26. Koczan, J. M., Lenneman, B. R., McGrath, M. J., and Sundin, G. W. 2011. Cell surface attachment structures contribute to biofilm formation and xylem colonization by Erwinia amylovora. Appl. Environ. Microbiol. 77:7031-7039.

27. Lagendijk, E. L., Validov, S., Lamers, G. E. M., de Weert, S., and Bloemberg, G. V. 2010. Genetic tools for tagging Gram-negative bacteria with mCherry for visualization in vitro and in natural habitats, biofilm and pathogenicity studies. FEMS Microbiol. Lett. 305:81-90.

28. Marques, L. L. R., De Boer, S. H., Ceri, H., and Olsen, M. 2003. Evaluation of biofilms formed by Clavibacter michiganensis subsp. sepedonicus. (Abstr.) Phytopathology 93:S57.

29. Marquez-Villavicencio, M., Groves, R. L., and Charkowski, A. O. 2011. Soft rot disease severity is affected by potato physiology and Pectobacterium taxa. Plant Dis. 95:232-241.

30. Moleleki, L. N, Onkendi, E. M., Mongae, A., and Kubheka, G. C. 2012. Characterisation of Pectobacterium wasabie causing blackleg and soft rot diseases in South Africa. Eur. J. Plant Pathol. 135:279-288.

31. Nabhan, S., De Boer, S. H., Maiss, E., and Wydra, K. 2012. Taxonomic relatedness between Pectobacterium carotovorum subsp. carotovorum, Pectobacterium carotovorum subsp. odoriferum and Pectobacterium carotovorum subsp. brasiliense subsp. nov. J. Appl. Microbiol. 113:904913.

32. Ngadze, E., Couthinho, T. A., Icishahayo, D., and van der Waals, J. E. 2012. Role of polyphenol oxidase, peroxidase, phenylalanine ammonia lyase, chlorogenic acid, and total soluble phenols in resistance of potatoes to soft rot. Plant Dis. 96:186-192.

33. Perez-Mendoza, D., Coulthurst, S. J., and Salmond, G. P. C. 2011. Nacetylglucosamine-dependent biofilm formation in Pectobacterium atrosepticum is cryptic and activated by elevated c-di-GMP levels. Microbiology 157:3340-3348.

34. Perombelon, M. C. M. 2002. Potato diseases caused by soft rot erwinias: An overview of pathogenesis. Plant Pathol. 51:1-12.

35. Powelson, M. L., and Apple, J. D. 1984. Soil and seed tubers as sources of inoculum of Erwinia carotovora pv. carotovora for stem soft rot of potatoes. Phytopathology 74:429-432.

36. Prithiviraj, B, Bais, H. P., Weir, T., Suresh, B., Najarro, E. H., Dayakar, B. V., Schweizer, H. P., and Vivanco, J. M. 2005. Down regulation of virulence factors of Pseudomonas aeruginosa by salicylic acid attenuates 
its virulence on Arabidopsis thaliana and Caenorhabditis elegans. Infect. Immun. 73:5319-5328.

37. Ramey, B. E., Koutsoudis, M., von Bodman, S. B., and Fuqua, C. 2004. Biofilm formation in plant-microbe associations. Curr. Opin. Microbiol. 7:602-609.

38. Toth, I. K., van der Wolf, J. M., Saddler, G., Lojkowska, E., Helias, V.,
Pirhonen, M., Tsror (Lahkim), L., and Elphinstone, J. G. 2011. Dickeya species: An emerging problem for potato production in Europe. Plant Pathol. 60:385-399.

39. van der Merwe, J. J., Coutinho, T. A., Korsten, L., and van der Waals, J. E. 2010. Pectobacterium carotovorum subsp. brasiliensis causing blackleg on potatoes in South Africa. Eur. J. Plant Pathol. 126:175-185. 